Check for updates

Cite this: RSC Adv., 2017, 7, 53472

Received 3rd July 2017

Accepted 15th November 2017

DOI: 10.1039/c7ra07339a

rsc.li/rsc-advances

\section{HPLC/PDA/ESI-MS/MS analysis of chamomile decoction and mechanism of its protective effects on aspirin-induced small bowel injuries}

\author{
Mohamed-Amine Jabri, (DD *a Najla Hajji, ${ }^{\text {a }}$ Dalanda Wannes, ${ }^{a}$ Haifa Tounsi, ${ }^{b}$ \\ Mourad Jridi, ${ }^{C}$ Afifa Abdellaoui, ${ }^{b}$ Moncef Nasri, ${ }^{C}$ Lamjed Marzouki ${ }^{a}$ and Hichem Sebai ${ }^{a}$
}

The aim of the present study is to evaluate the effect of chamomile (Matricaria recutita L.) decoction extract (CDE) on aspirin-induced small bowel injuries. The chemical composition of CDE was analysed by LC-HRESIMS. Experimental animals received CDE (100 $\mathrm{mg} \mathrm{kg}^{-1}$, p.o. P.C.) before induction of intestinal injuries by oral aspirin administration. Chromatographic analysis has allowed the identification of 15 phenolic compounds, especially phenolic acids and flavonoids. The intestinal disturbances were assessed by histopathological and biochemical examinations. In vivo, we found that aspirin administration caused intestinal histological alterations accompanied by an oxidative stress status as assessed by increase in a lipoperoxidation and depletion of non-enzymatic antioxidant levels and antioxidant enzyme activities, as well as an intestinal overload of reactive oxygen species such as $\mathrm{H}_{2} \mathrm{O}_{2}, \mathrm{OH}^{\cdot}$ and $\mathrm{O}_{2}{ }^{\cdot-}$. We also showed that aspirin treatment significantly increased the pro-inflammatory mediator (IL-6, IL-1 $\beta$ and TNF- $\alpha$ ) levels in plasma. CDE treatment suppressed all the histological and biochemical disturbances induced by aspirin intoxication.

\section{Introduction}

At present, the family of non-steroidal anti-inflammatory drugs (NSAIDs) has many therapeutic indications, both in human and veterinary medicine, with a broad spectrum of antiinflammatory, analgesic, antipyretic and antiplatelet pharmacological activities. ${ }^{\mathbf{1}}$ The prototype of these drugs, which we will take as a reference, is aspirin. ${ }^{2,3}$ The therapeutic effects of aspirin arise from its ability to inhibit the synthesis of prostaglandins and their derivatives. This inhibition results from the blocking of the various cyclooxygenase isoforms (COX 1 and 2). ${ }^{3}$ However, aspirin used at antiaggregative doses (75-325 mg per day) also induces gastroduodenal toxicity. ${ }^{4,5}$ Indeed, previous studies have shown that aspirin used at $10 \mathrm{mg}$ per day inhibited prostaglandin synthesis leading to gastric mucosa injuries. This disease can also be related to the activation of neutrophils and thus to excessive production of reactive oxygen species (ROS). ${ }^{6}$

Oxidative stress is related to an excessive production of free radicals which are highly reactive chemical species because their peripheral electronic layer contains a very unstable single electron.

${ }^{a}$ Laboratoire de Physiologie Fonctionnelle et Valorisation des Bio-Ressources, Institut Supérieur de Biotechnologie de Béja, Université de Jendouba, Avenue Habib Bourguiba - B.P. 382, 9000 Béja, Tunisia. E-mail: jabri.amino@gmail.com; Fax: +21678459 098; Tel: +21693484751

${ }^{b}$ Laboratoire d'anatomie pathologique humaine et expérimentale, Institut Pasteur de Tunis, 13, Place Pasteur, BP-74, Tunis 1002, Tunisia

${ }^{c}$ Laboratoire de Génie Enzymatique et de Microbiologie, Ecole Nationale d'Ingénieurs de Sfax, Université de Sfax, B.P. 1173, 3038 Sfax, Tunisia
In the physiological condition, free radicals are produced in small quantities during cell respiration and metabolism. ${ }^{7}$ However, the intracellular imbalance between their genesis and degradation results in oxidative stress. This situation was accompanied by a significant damage such as the of peroxidation of lipids membrane, oxidation of enzymatic and structural proteins as well as breakdown of nucleic acids leading to cells death., ${ }^{\mathbf{8} 9}$

The chamomile (Matricaria recutita $\mathrm{L}$.) is a plant belonging to the family of Asteraceae. It is one of the best known medicinal plants, which is included in the pharmacopoeias of 26 countries all over the world, including Tunisia. ${ }^{\mathbf{1 0 1 1}}$ The main therapeutic effects of chamomile due to its antioxidant properties are antiinflammatory, anxiolytic, sedative and especially digestive. ${ }^{\mathbf{1 2}}$ Indeed, chamomile has been widely used in the treatment of the majority of gastrointestinal diseases such as flatulence, indigestion, nausea, vomiting, ${ }^{\mathbf{1 3}}$ gastric ulcer $^{\mathbf{1 0}}$ and diarrhea. ${ }^{\mathbf{1 4}}$ Chamomile is generally safe for consumption, although patients are hypersensitive to ragweed. ${ }^{13}$

In the present investigation we evaluated the chemical composition of chamomile decoction extract (CDE), as well as the relationship between histological injuries, inflammation and oxidative stress induced by aspirin intoxication, and the protection offered by CDE administration.

\section{Experimental}

\section{Reagents}

Methanol (PubChem CID: 887), pyrogallol (PubChem CID: 1057), DNTB (PubChem CID: 15325), BSA (PubChem AID: 
386950), TBA (PubChem CID: 5759), TCA (PubChem CID: 23681045), beta-D-2-deoxyribose (PubChem CID: 439576), GSH (PubChem CID: 124886), BHT (PubChem CID: 31404), diethyl ether (PubChem CID: 3283) and $\mathrm{NaCl}$ (PubChem CID: 5234) were purchased from Sigma-Aldrich Co. (Germany).

\section{Preparation of chamomile decoction extract}

Chamomile flowers were collected from the region of Beja (North-West of Tunisia) during March 2016 and identified by Dr Imen Bel Hadj Ali, Associate professor in the Higher Institute of Biotechnology of Béja-Tunisia. The voucher specimens (No. M121) have been deposited in the herbarium of the Higher Institute of Biotechnology of Béja since 2012. The plant material was later dried in an incubator at $40{ }^{\circ} \mathrm{C}$ during 72 hours and powdered in an electric blender. The decoction was made with double distilled water $(1 / 5 ; \mathrm{w} / \mathrm{v})$ at $100{ }^{\circ} \mathrm{C}$ during five minutes under magnetic agitation and the homogenate was filtered through a colander ( $0.5 \mathrm{~mm}$ mesh size). Finally, the obtained extract (CDE) was stored at $-80{ }^{\circ} \mathrm{C}$ until used.

\section{Characterization of phenolic compounds of CDE by liquid chromatography-high resolution electrospray ionization mass spectrometry (LC-HRESIMS) analysis}

One hundred $\mathrm{mg}$ of CDE was dissolved in $100 \mathrm{~mL}$ of $10 \%$ methanol, filtered and then $1 \mathrm{~mL}$ was transferred into LC-MS vials. Reversed-phase column (Pursuit XRs ULTRA 2.8, C18, $100 \times 2 \mathrm{~mm}$, Agilent Technologies, UK) was used to carry out HPLC analyses. Twenty $\mu \mathrm{L}$ of the sample was injected at a column temperature set at $30{ }^{\circ} \mathrm{C}$. Mobile phases consisted of $0.1 \%$ formic acid in water $(\mathrm{A})$ and $0.1 \%$ formic acid in methanol (B). A gradient program was used for separation at a flow rate of $1 \mathrm{~mL} \mathrm{~min}^{-1}$. Mobile phases consisted of an initial composition of $100 \%$ solvent A, with a gradient of $100 \%$ solvent B over 20 minutes, hold at $100 \%$ solvent B for $5 \mathrm{~min}$ and $100 \%$ solvent A

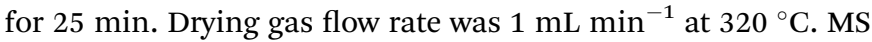
was operated in the positive ion mode in a mass range of 100$2000 \mathrm{~m} / \mathrm{z}$. High resolution mass spectral data were obtained on a Thermo Instruments ESI-MS system (LTQ XL/LTQ Orbitrap Discovery, UK) connected to a Thermo Instruments HPLC system (Accela PDA detector, Accela PDA autosampler and Accela Pump).

\section{Animals and treatment}

Adult male Wistar rats (weighing $194 \pm 15.5$ g, 15 weeks old and housed five per cage) were purchased from Pasteur Institute of Tunis. All animal procedures were performed in accordance with the Guidelines for Care and Use of Laboratory Animals of Tunis University and approved by the Animal Ethics Committee of National Institute of Health (1985) ${ }^{15}$ They were provided with standard food (BADR, Utique, TN) and water ad libitum and maintained in animal house under controlled temperature $\left(22 \pm 2{ }^{\circ} \mathrm{C}\right)$ with a $12 / 12 \mathrm{~h}$ light-dark cycle.

Animals were divided into four groups of 10 animals each. The animals were orally treated for 7 days with bidistilled water (group I and III) or with $100 \mathrm{mg} \mathrm{kg}^{-1}$ body weight (b.w.) of CDE (group II and IV), preliminary experiment indicated that
$100 \mathrm{mg} \mathrm{kg}^{-1}$ b.w. CDE was the lowest dose that give a significant protective effect. The last day, after $24 \mathrm{~h}$ of fasting and two hours after the last gavage, groups III and IV was intoxicated by acute administration of aspirin (ASPR) $\left(200 \mathrm{mg} \mathrm{kg}^{-1} \text {, b.w., p.o. }\right)^{16}$ while groups I and II received a physiological solution $(\mathrm{NaCl}$, $0.9 \%$, p.o.).

Two hours later, animals were sacrificed. Blood was collected in heparinized tubes. After centrifugation at $3000 \mathrm{~g}$ during $15 \mathrm{~min}$, plasma was treated for cytokine determination.

\section{Tissues preparation}

The small intestine was rapidly excised, rinsed in $\mathrm{NaCl} 0.9 \%$ and homogenized in phosphate buffer saline $\left(\mathrm{KH}_{2} \mathrm{PO}_{4} / \mathrm{K}_{2} \mathrm{HPO}_{4}\right.$, $50 \mathrm{mM}, \mathrm{pH}$ 7.4) with Potter-Elvehjem homogenizer. After centrifugation at $10000 \mathrm{~g}$ for $10 \mathrm{~min}$ at $4{ }^{\circ} \mathrm{C}$, supernatant was used for the biochemical determination of protein, MDA, antioxidant enzyme activities GSH, thiol groups and ROS production.

\section{Histopathological analysis}

Immediately after the sacrifice, samples of small bowel were harvested and washed with ice-cold saline. Tissue fragments were fixed in $10 \%$ neutral buffered formalin solution, dehydrated in increasing concentrations of ethanol and xylene, and then embedded in paraffin. $5 \mu \mathrm{m}$ thick sections were cut, deparaffinized, hydrated and stained with hema-toxylin and eosin (HE). The intestine sections were examined in a blind fashion in all treatments.

\section{Lipid peroxidation determination}

The lipid peroxidation is detected by the determination of malondialdehyde (MDA) production using the thiobarbituric acid method. ${ }^{17}$ Briefly, aliquots from small bowel tissues homogenates were mixed with BHT-trichloroacetic acid (TCA) solution containing $1 \%$ BHT (w/v) dissolved in $20 \%$ TCA $(w / v)$ and centrifuged at $1000 \times g$ for $5 \mathrm{~min}$ at $4{ }^{\circ} \mathrm{C}$. Then, the supernatant was mixed with $0.5 \mathrm{NaCl}$ and $120 \mathrm{mM}$ TBA (thiobarbituric acid) in $26 \mathrm{mM}$ Tris and heated in water bath at $80^{\circ} \mathrm{C}$ for $10 \mathrm{~min}$. After cooling, the absorbance of the resulting chromophore was determined at $532 \mathrm{~nm}$. MDA levels were determined by using an extinction coefficient for MDA-TBA complex of $1.56 \times 105 \mathrm{M}^{-1} \mathrm{~cm}^{-1}$.

\section{Non-enzymatic antioxidants measurement}

GSH levels determination was carried out by Sedlak and Lindsay method. ${ }^{18}$ Briefly, $500 \mu \mathrm{L}$ of tissue homogenate prepared in $20 \mathrm{mM}$ EDTA, (pH 4.7) were added to the $400 \mu \mathrm{L}$ of cold distilled water and $100 \mu \mathrm{L}$ of TCA solution (50\%). The samples were vortexed and centrifuged at $1200 \times g$ during $15 \mathrm{~min}$. Then, $2 \mathrm{~mL}$ of supernatant were mixed with $400 \mu \mathrm{L}$ of $400 \mathrm{mM}$ Tris-buffer (pH 8.9) and $10 \mu \mathrm{L}$ of $10 \mathrm{mM}$ DTNB. Optical density was measured at $412 \mathrm{~nm}$ against blank tube without jejunal homogenate.

Sulfhydryl groups (-SH) was performed according to Ellman's method. ${ }^{19}$ Briefly, small bowel homogenates were mixed 
with $100 \mu \mathrm{L}$ of $20 \mathrm{mM}$ EDTA (ethylene tetra acetic acid) pH 8.2. Then, the reaction mixture was vortexed and its optical density was measured at $412 \mathrm{~nm}$ (A1). Then, $100 \mu \mathrm{L}$ of $10 \mathrm{mM}$ DTNB were added, incubated during $15 \mathrm{~min}$ and the absorbance of the sample was measured at $412 \mathrm{~nm}$ (A2). The sulfhydryl groups concentration was calculated using this expression: (A2 - A1 - B) $\times 1.57 \mathrm{mM}$. The results were expressed as $\mu \mathrm{mo}$ of thiol groups per mg of protein.

\section{Antioxidant enzymes activities assays}

The method of Misra and Fridovich was used to determine the activity of superoxide dismutase (SOD). ${ }^{20}$ Briefly, small bowel homogenate was added to $2 \mathrm{~mL}$ reaction mixture containing 20 $\mu \mathrm{L}$ of epinephrine $\left(5 \mathrm{mg} \mathrm{mL} \mathrm{m}^{-1}\right), 10 \mu \mathrm{L}$ of bovine catalase $(0.4 \mathrm{U}$ $\mu \mathrm{L}^{-1}$ ) and $62.5 \mathrm{mM}$ of sodium carbonate/bicarbonate buffer $\mathrm{pH}$ 10.2. Changes in absorbance were measured at $480 \mathrm{~nm}$. Catalase activity was determined according to the method described by Aebi. ${ }^{21}$ The reaction mixture contained $33 \mathrm{mM} \mathrm{H}_{2} \mathrm{O}_{2}$ in $50 \mathrm{mM}$ phosphate buffer $\mathrm{pH} 7.0$ and CAT activity was calculated using the extinction coefficient of $40 \mathrm{mM}^{-1} \mathrm{~cm}^{-1}$ for $\mathrm{H}_{2} \mathrm{O}_{2}$. The GPx activity was quantified following the method described by Flohé and Günzler. ${ }^{22}$ Briefly, $1 \mathrm{~mL}$ of reaction mixture containing $0.2 \mathrm{~mL}$ of small bowel supernatants, $0.4 \mathrm{~mL}$ of $\mathrm{H}_{2} \mathrm{O}_{2}(5$ $\mathrm{mM}), 0.2 \mathrm{~mL}$ of phosphate buffer $0.1 \mathrm{M} \mathrm{pH} 7.4$ and $0.2 \mathrm{~mL}$ of $\mathrm{GSH}(4 \mathrm{mM})$ was incubated at $37^{\circ} \mathrm{C}$ for $1 \mathrm{~min}$ and the reaction was stopped by addition of $0.5 \mathrm{~mL}$ TCA $(5 \%, \mathrm{w} / \mathrm{v})$. After centrifugation at $1500 \mathrm{~g}$ for $5 \mathrm{~min}$, aliquot $(0.2 \mathrm{~mL})$ from supernatant was combined with $0.5 \mathrm{~mL}$ DTNB $(10 \mathrm{mM})$ and $0.5 \mathrm{~mL}$ of phosphate buffer $0.1 \mathrm{M} \mathrm{pH} 7.4$ and absorbance was measured at $412 \mathrm{~nm}$. The GPx activity was expressed as nmol of GSH consumed per min per mg protein.

\section{Protein determination}

Protein concentration was determined according to Hartree ${ }^{23}$ which is a slight modification of the Lowry method. Serum albumin was used as standard.

\section{Measurement of ROS production}

The intestine $\mathrm{H}_{2} \mathrm{O}_{2}$ level was performed according to Dingeon et $a{ }^{24}{ }^{24}$ Briefly, in the presence of peroxidase, the hydrogen peroxide reacts with $p$-hydroxybenzoic acid and 4-aminoantipyrine leading to a quantitative formation of a quinoneimine which has a pink color detected at $505 \mathrm{~nm}$.

The hydroxyl radical level was determined using Payá et al. method. ${ }^{25}$ Briefly, after oxidation of deoxyribose by hydroxyl radical generated by the $\mathrm{Fe}^{3+}$-ascorbate-EDTA- $\mathrm{H}_{2} \mathrm{O}_{2}$ pathway and incubation with intestine homogenate at $37{ }^{\circ} \mathrm{C}$ for one hour, the reaction mixture was stopped by adding of TCA $(2.8 \%)$ and TBA (1\%) and boiled at $100{ }^{\circ} \mathrm{C}$ for $20 \mathrm{~min}$. Changes in absorbance were recorded at $532 \mathrm{~nm}$ against blank containing deoxyribose and buffer.

Superoxide radical was estimated according to Marklund and Marklund ${ }^{\mathbf{2 6}}$ with slight changes. Briefly, intestinal homogenates were incubated in Tris-HCl buffer, and then pyrogallol was added to the reaction mixture which will then be incubated at $25{ }^{\circ} \mathrm{C}$ for four-minutes. The reaction has been stopped by $\mathrm{HCl}$ addition and absorbance was read at $420 \mathrm{~nm}$ against the blank.

\section{Assessment of IL-6, IL-1 $\beta$ and TNF- $\alpha$ in plasma}

Cytokines (IL-6, IL-1 $\beta$ and TNF- $\alpha$ ) levels were determined in the plasma samples using standard sandwich enzyme-linked immunosorbent assay (ELISA) kit according to the manufacturer's instruction and expressed in pg per $\mathrm{mg}$ of proteins.

\section{Statistical analysis}

The data were analyzed by one-way analysis of variance (ANOVA) and were expressed as means \pm standard error of the mean (S.E.M.). The data are representative of 6 independent experiments. All statistical tests were two-tailed, and a $p$ value of 0.05 or less was considered significant.

\section{Results}

\section{Liquid chromatography-high resolution electrospray ionization mass spectrometry (LC-HRESIMS) analysis of chamomile decoction extract}

The HPLCPDAESI-MS/MSLC-HRESIMS analysis of CDE revealed the presence of phenolic acids and flavonoids. This technique allowed to the identification of seven phenolic acids which include gallic acid, protocatechuic acid, 4-O-caffeoylquinic acid, caffeic acid, $p$-coumaric acid, 3,4-di-O-caffeoylquinic acid and 4,5-di-O-caffeoylquinic acid (Table 1 ). The chromatographic elution profile of flavonoids (Fig. 1) showed eight compounds, including six known flavonoids such as rutin, naringin, quercetin, kampherol, apegenin and cirsiliol (Table 1).

\section{Histological evaluations}

Histological observations of the small bowel of aspirin treated rats had manifested extensive damages in the intestinal mucosa as assessed by villi congestion, edema and leucocytes infiltration (Fig. 2). Pretreatment with $\operatorname{CDE}\left(100 \mathrm{mg} \mathrm{kg}^{-1}\right.$, b.w., p.o.) for seven days had comparatively better protection of the intestinal mucosa as seen by reduction in inflammatory infiltrates and edema as well as reepithelialization of the small bowel mucosa (Table 2).

\section{Effect of aspirin and CDE on small bowel lipid peroxidation}

As shown in Table 2, animals exposed to ASPR-induced small bowel injuries showed noticeable higher intestinal's MDA levels. However, CDE pretreatment reversed intestinal lipoperoxidation induced by aspirin intoxication.

\section{Effect of aspirin and CDE on small bowel antioxidant enzyme activities}

We reported in Table 2 the effect of ASPR and CDE on intestinal antioxidant enzyme activities. As expected, aspirin administration was found to cause a significant decrease in SOD, CAT and GPx activities when compared with control group. CDE pretreatment significantly prevented the depletion of antioxidant enzyme activities induced by aspirin intoxication. 
Table 1 Liquid chromatography-high resolution electrospray ionization mass spectrometry (LC-HRESIMS) analysis of CDE

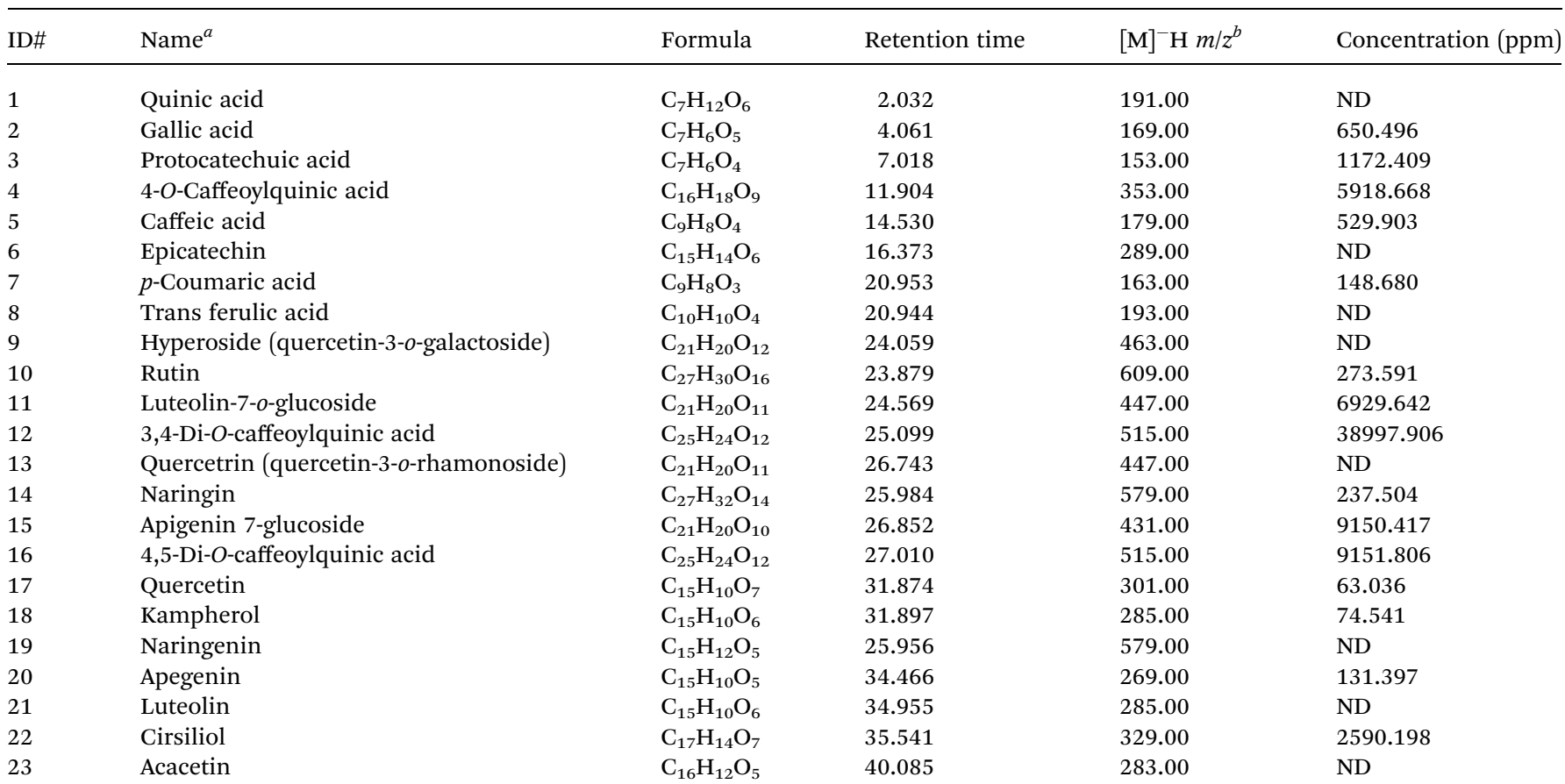

${ }^{a}$ The compounds are suggested according to the dictionary of natural products (DNP 23.1, 2015 on DVD) and the characteristic fragmentation pattern. ${ }^{b}$ The formulas were deduced from the quasi molecular ion peak $[\mathrm{M}+\mathrm{H}]^{+}$.

\section{Effect of aspirin and CDE on small bowel non-enzymatic antioxidants}

As it is obvious in Table 3, the levels of reduced glutathione and thiol groups were significantly reduced in the intestines of aspirin treated rats. However $\operatorname{CDE}\left(100 \mathrm{mg} \mathrm{kg}^{-1}\right.$, b.w., p.o.) pretreatment significantly protected against this decrease when compared to ASPR group.

\section{Effect of aspirin and CDE on small bowel ROS production}

Rats treated with aspirin (100 $\mathrm{mg} \mathrm{kg}^{-1}$, b.w., p.o.) showed a marked intestinal overload of reactive oxygen species such as hydrogen peroxide (Fig. 3A), hydroxyl radical (Fig. 3B) and superoxide anion (Fig. 3C) than all groups. However, CDE pretreatment significantly protected against ASPR-induced ROS deregulation and restored the small bowel redox balance.

\section{Effect of aspirin and CDE on serum cytokines}

Serum IL-6 (Fig. 4A), IL-1 $\beta$ (Fig. 4B) and TNF- $\alpha$ (Fig. 4C) levels were augmented in the aspirin treated rats when compared to the normal group while CDE administration has effectively protected against this increase, showing a powerful antiinflammatory activity of CDE against harmful effects of aspirin.

\section{Discussion}

We firstly showed that the chemical analysis of the CDE using LC-HRESIMS allowed to the identification of 15 phenolic compounds, especially phenolic acids and flavonoids such as rutin, luteolin-7-o-glucoside, naringin, apigenin 7-glucoside, quercetin, kampherol, apegenin and cirsiliol. Indeed, flavonoids are natural polyphenols contained as glucosidic derivatives in many fruits and vegetables and in certain beverages such as tea, wine and beer. ${ }^{27,28}$ Therefore, owing to their antiinflammatory and scavenging of oxygen derived free radicals activities, $^{29}$ flavonoids are known to exhibit several other potential beneficial health effects as anticancer, ${ }^{30}$ antithrombotic, $^{31}$ antiviral, ${ }^{32}$ cardio-protective and anti-allergic activities. $^{29}$

In vivo, our results clearly showed that single oral administration of aspirin (200 $\mathrm{mg} \mathrm{kg}^{-1}, \mathrm{PC}$ ) causes severe lesions in the intestinal mucosa. These results are in agreement with other studies showing that this dosage of aspirin is very effective for the induction of small intestine lesions., ${ }^{\mathbf{4 3}, 34}$ Indeed, the histological analyzes revealed that acute administration of aspirin induces structural modifications as assessed by intestinal mucous and submucosa lesions. These latter are accompanied by edema, surface coating and epithelial cells alterations, as well as leukocyte infiltration. In fact, prostaglandin (PGs) deficiency within the digestive mucosa is considered as the major pathogenic mechanism of the aspirin-induced digestive system diseases. Although it is well established that the deficit in endogenous PGs does not directly causes the digestive lesions, but it plays a central role in the pathogenic process by making the mucosa more vulnerable to the aggression. ${ }^{3,35} \mathrm{~A}$ focal decrease in the mucosal blood flow preceding the appearance of lesions has been observed in humans ${ }^{36}$ as well as in several experimental models. $^{37,38}$ Subacute CDE pretreatment reduces aspirininduced histological changes. Previously, we also showed 


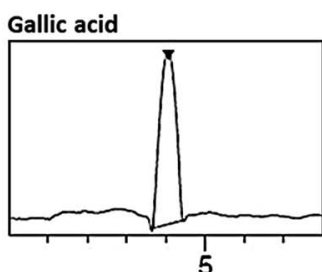

Protocatechuic acid

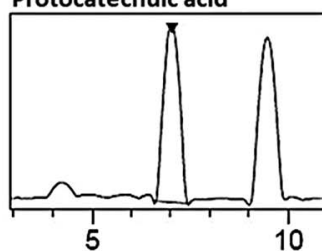

4-0-caffeoylquinic acid

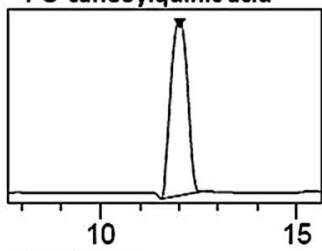

Caffeic acid

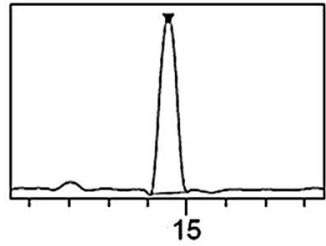

p-coumaric acid

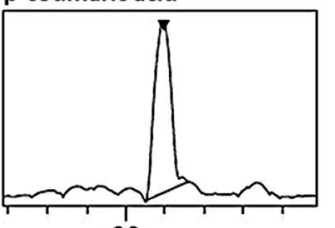

20

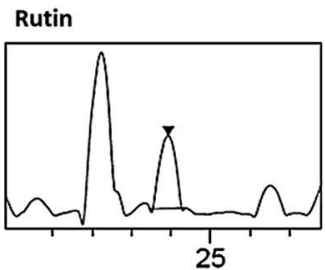

Luteolin-7-o-glucoside

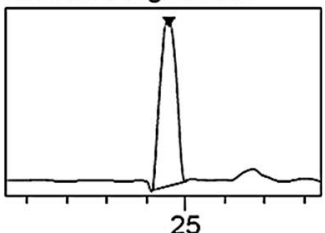

3,4-di-O-caffeoylquinic acid

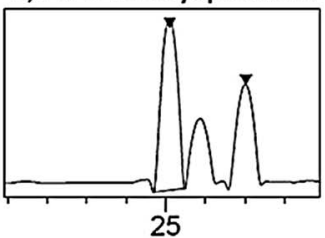

Naringin

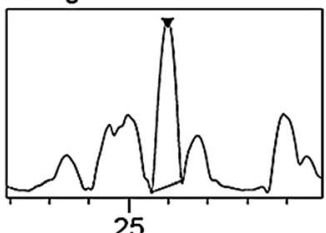

Apegenin-7-o-glucoside

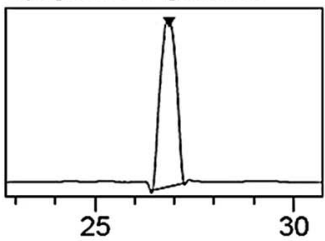

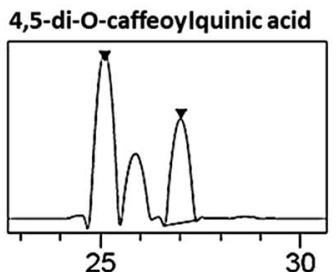

Quercetin

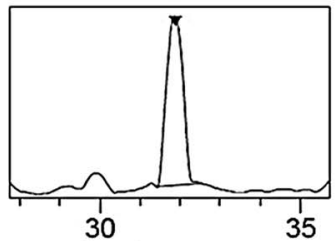

Kampherol

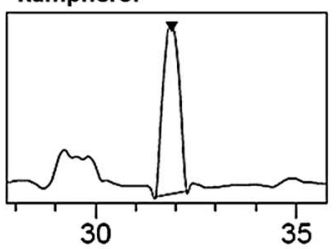

Apigenin

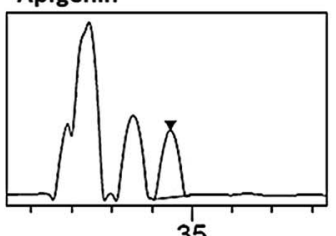

35

Cirsiliol

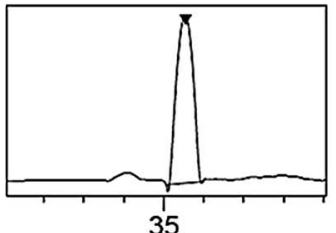

Fig. 1 Representative LC-HRESIMS of phenolic compounds in the chamomile decoction extract (CDE) (assignments of peaks are given in Table 1).

that CDE has been shown to reduce alterations in gastric epithelium induced by ethanol ${ }^{10}$ as well as diarrhea induced by castor oil intoxication. ${ }^{14}$

Subacute administration of aspirin $\left(200 \mathrm{mg} \mathrm{kg}^{-1}\right.$; PC) altered also the small intestine redox balance, leading to an increase of lipoperoxidation, a depletion of antioxidant enzymes activity such as superoxide dismutase (SOD), catalase (CAT) and glutathione peroxidase (GPx), as well as the fall in the levels of the sulfhydryl groups and GSH. The same effect was also found by Hong et al. ${ }^{39}$ and Nair et al. ${ }^{40}$ However, an abundant literature is available concerning the relationship between oxidative stress and inflammatory diseases, particularly in the digestive tract. ${ }^{5,41,42}$ Indeed, reactive oxygen species have been shown to induces intestinal inflammation leading to mucosa lesions. ${ }^{43,44}$ Thus, Mulder et al. ${ }^{45}$ found a SOD activity and metallothionein concentrations decrease during inflammatory bowel disease and Sido et al. ${ }^{45}$ report a decrease in the glutathione synthesis, a key molecule of GPx activity, which intervenes with catalases in the degradation of hydrogen peroxide. ${ }^{46,47}$ The subacute CDE administration has significantly protected against aspirin-induced oxidative stress. In fact, the richness of this extract in phenolic compounds gives it the ability to protect against toxicity and oxidative stress induced by aspirin administration.

In addition to deleterious effects on the antioxidant enzymes activity and non-enzymatic antioxidants, administration of aspirin has been accompanied by an increase of reactive oxygen species production such as hydrogen peroxide $\left(\mathrm{H}_{2} \mathrm{O}_{2}\right)$, superoxide anion $\left(\mathrm{O}_{2}{ }^{--}\right)$and hydroxyl radical $\left(\mathrm{OH}^{\circ}\right)$ in the intestine. The hydroxyl radicals are the most damaging ROS of oxidative stress, because of their extreme reactivity and their ability to attack all biological materials (DNA, proteins and lipids). These radicals can also react with the polyunsaturated fatty acids of the membrane phospholipids and lipoproteins leading to the initiation of lipid peroxidation chains. ${ }^{48,49}$ The superoxide radical's toxicity seems rather to be exercised in an indirect manner by reacting with $\mathrm{H}_{2} \mathrm{O}_{2}$ leading to $\mathrm{OH}$ radicals generation. $^{50}$ Furthermore, the spontaneous dismutation of 


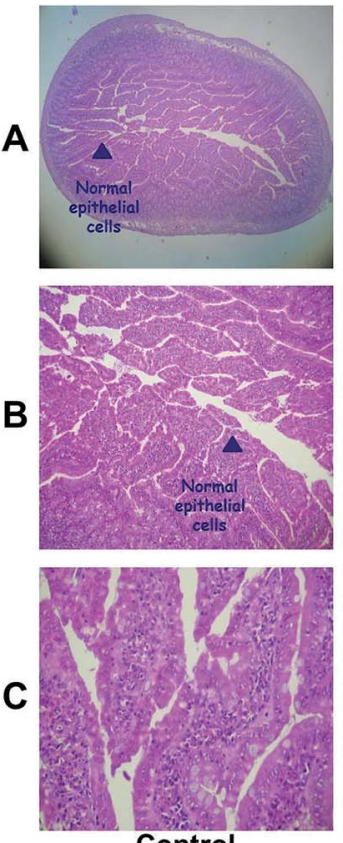

Control
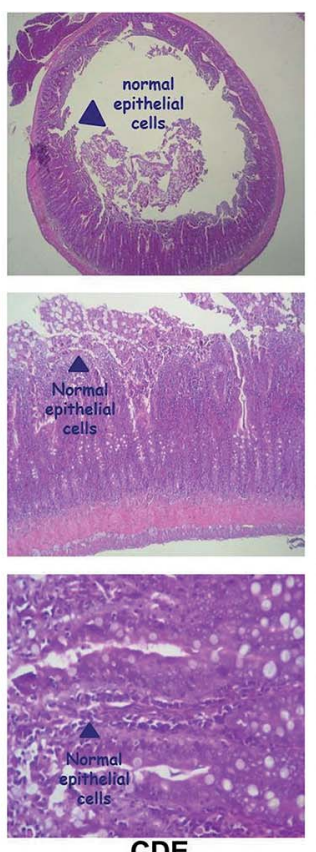

CDE
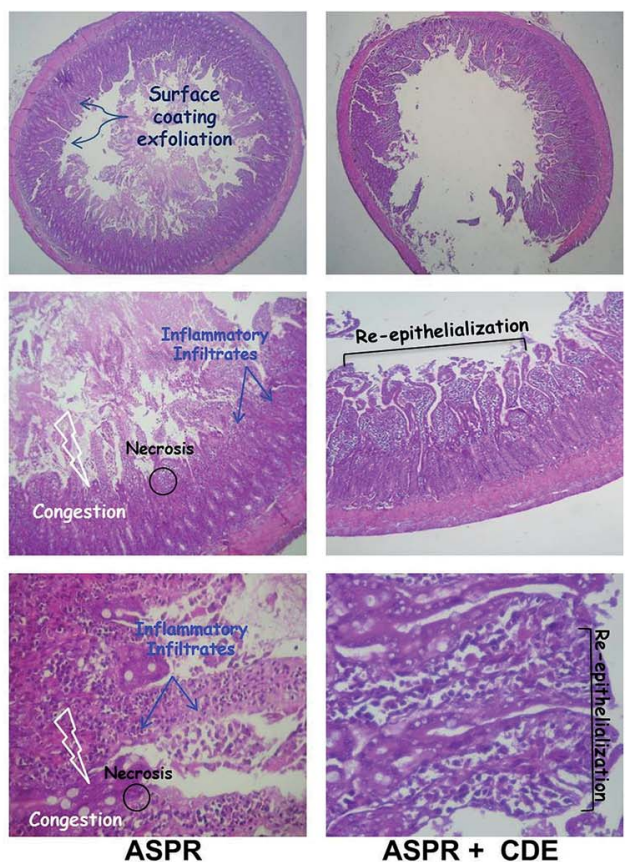

Fig. 2 Effect of chamomile decoction extract (CDE) and aspirin (ASPR) in the intestinal histology. Animals were treated with CDE (100 mg kg ${ }^{-1}$, b.w., p.o.) or bidistilled water, challenged with a single oral administration of aspirin $\left(200 \mathrm{mg} \mathrm{kg}^{-1}\right.$, b.w., p.o.) or $\mathrm{NaCl}(9 \%)((\mathrm{A}) \mathrm{magnification} 5 \times$, (B) $10 \times$ and (C) $40 \times)$.

Table 2 Effect of chamomile decoction extract (CDE) on aspirin (ASPR)-induced small bowel injury. Animals were treated with CDE (100 $\mathrm{mg} \mathrm{kg}^{-1}$, b.w., p.o.) or bidistilled water, challenged with a single oral administration of aspirin (200 $\mathrm{mg} \mathrm{kg}^{-1}$, b.w., p.o.) or $\mathrm{NaCl}(9 \%)$. The data are expressed as mean \pm S.E.M. $(n=10)$, *: $p<0.05$ compared to control group and \#: $p<0.05$ compared to colitis group

\begin{tabular}{lll}
\hline Groups & Small bowel injury index & Protection (\%) \\
\hline Control & - & - \\
CDE & - & - \\
ASPR & $5.28 \pm 0.72^{*}$ & - \\
ASPR + CDE & $1.53 \pm 0.48^{\#}$ & 71.02 \\
\hline
\end{tabular}

superoxide anion is sufficiently rapid, so that hydrogen peroxide production is itself a deleterious phenomenon via the Fenton reaction. ${ }^{51}$ However, all the radical damage induced by aspirin seems to be limited by the CDE administration; in fact the chamomile decoction is very rich in protocatechuic acid, apigenin-7-glucoside, quercetin, kampherol and naringin. These antioxidant molecules can reduce this toxicity of aspirin because they have a structure that allows them to trap free radicals by neutralizing them, which prevents ROS from reaching their biological targets. ${ }^{52}$ In agreement with these data, we have shown in a previous work that CDE inhibits the human neutrophils ROS production. ${ }^{53}$

More importantly, we have shown that CDE prevents against aspirin intoxication induced inflammation as assessed by a significant increase in plasma cytokines such as IL- $1 \beta$, IL- 6 and TNF- $\alpha$. Indeed, several studies have shown that aspirin is associated with an inflammatory state via the expression of proinflammatory cytokines. ${ }^{4,36}$ Although, inflammatory state and oxidative stress are intimately linked, as shown by the constant elevation of oxidative stress markers during inflammatory bowel disease. ${ }^{54}$ Thus, taking antioxidants is an important therapeutic strategy for fighting

Table 3 Effect of chamomile decoction extract (CDE) on aspirin (ASPR)-induced small bowel oxidative stress. Animals were treated with CDE (100 mg kg ${ }^{-1}$, b.w., p.o.) or bidistilled water, challenged with a single oral administration of aspirin (200 mg kg ${ }^{-1}$, b.W., p.o.) or $\mathrm{NaCl}(9 \%)$. MDA, nmol of MDA per mg protein; SOD, units per mg protein; CAT, $\mu$ mol of $\mathrm{H}_{2} \mathrm{O}_{2}$ consumed per min per mg protein; GPx, nmol GSH oxidized per min

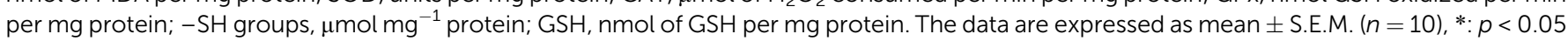
compared to control group and \#: $p<0.05$ compared to colitis group

\begin{tabular}{llllll}
\hline Treatment & MDA & SOD & CAT & GPx & -SH groups \\
\hline Control & $1.87 \pm 0.34$ & $5.37 \pm 0.41$ & $9.20 \pm 0.55$ & $10.62 \pm 0.88$ & $74.92 \pm 3.78$ \\
CDE & $1.61 \pm 0.27$ & $5.96 \pm 0.33$ & $10.03 \pm 0.74$ & $11.23 \pm 0.71$ & $81.95 \pm 2.34$ \\
ASPR & $4.27 \pm 0.36^{*}$ & $2.70 \pm 0.41^{*}$ & $5.52 \pm 0.54^{*}$ & $6.53 \pm 0.77^{*}$ & $38.06 \pm 3.75^{*}$ \\
ASPR + CDE & $2.30 \pm 0.38^{\#}$ & $4.80 \pm 0.29^{\#}$ & $8.32 \pm 046^{\#}$ & $9.52 \pm 0.64^{\#}$ & $67.63 \pm 4.88^{\#}$
\end{tabular}


(A)

(B)

(C)
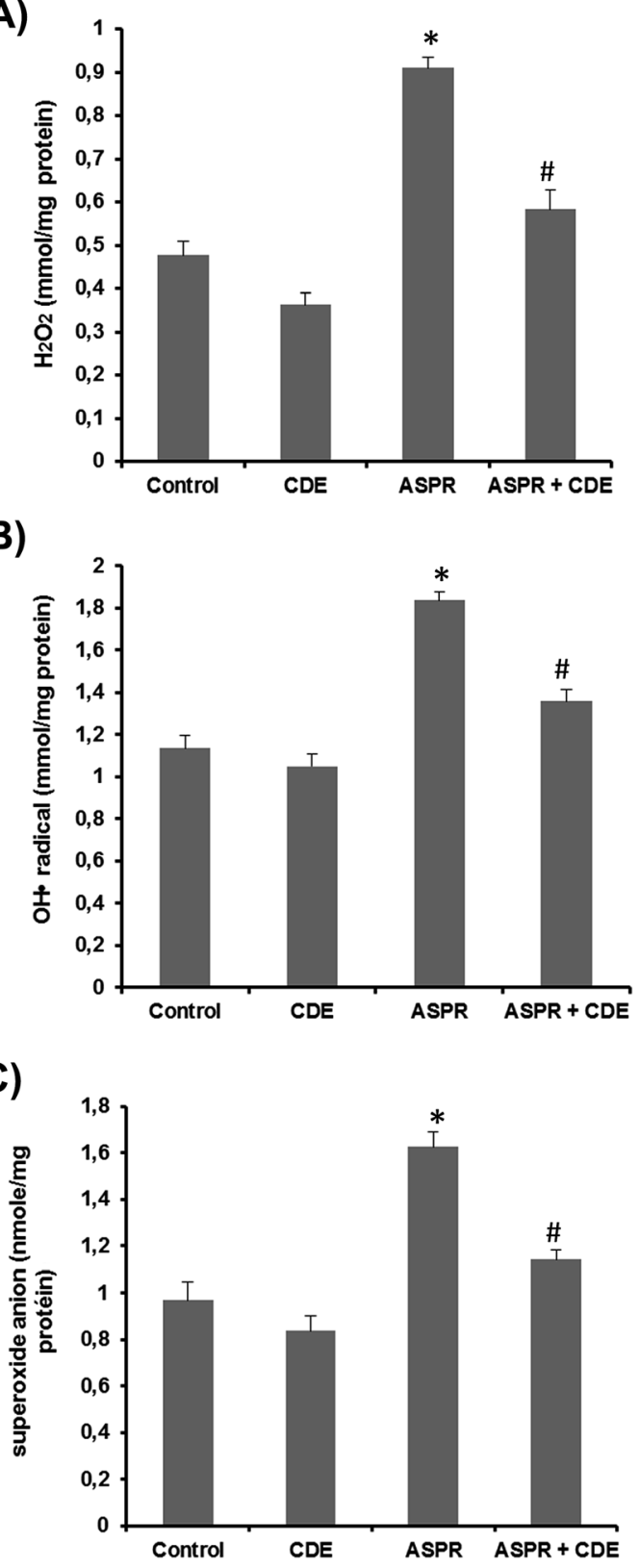

Fig. 3 Effect of chamomile decoction extract (CDE) on aspirin (ASPR)induced disturbance in small bowel hydrogen peroxide (A), hydroxyl radical $(B)$ and superoxide anion $(C)$. Animals were treated with $C D E$ (100 $\mathrm{mg} \mathrm{kg}^{-1}$, b.w., p.o.) or bidistilled water, challenged with a single oral administration of aspirin (200 $\mathrm{mg} \mathrm{kg}^{-1}$, b.w., p.o.) or $\mathrm{NaCl}(9 \%)$. The data are expressed as mean \pm S.E.M. $(n=10), *: p<0.05$ compared to control group and \#: $p<0.05$ compared to colitis group.

inflammation. In this context, the same anti-inflammatory effect of chamomile was also found in rats against pulmonary fibrosis,${ }^{55}$ as well as in cultured macrophages..$^{56}$ Moreover, 3,4-di-O-caffeoylquinic acid (CQC) which was identified with abandoned amount in CDE (38997.906 ppm) possesses an important anti-inflammatory activity by inhibiting NO release, inducible nitric oxide synthase and cyclooxygenase-2 expression, as well as granulocyte macrophage colonystimulating factor overproduction. ${ }^{57,58}$
(A)

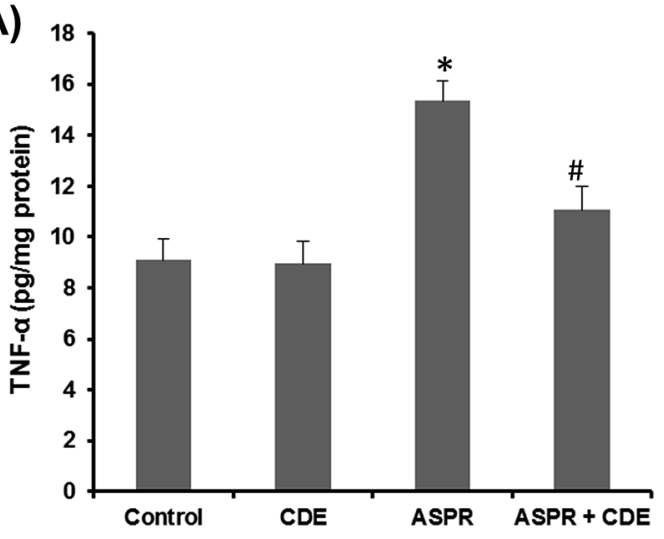

(B)

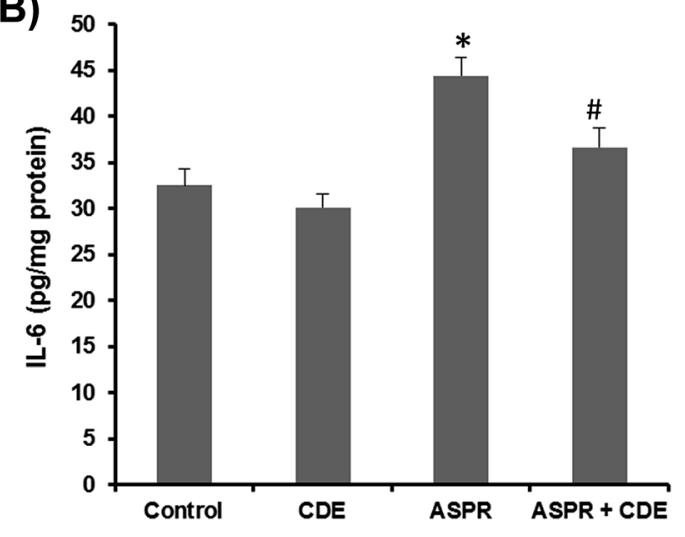

(C)

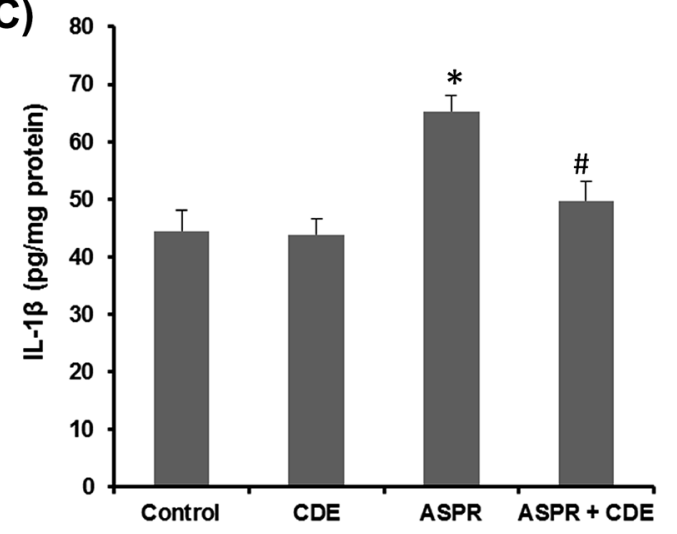

Fig. 4 Effect of chamomile decoction extract (CDE) on aspirin (ASPR)induced disturbance in small bowel TNF- $\alpha$ (A), IL-6 (B) and IL-1 (C). Animals were treated with CDE (100 mg kg ${ }^{-1}$, b.w., p.o.) or bidistilled water, challenged with a single oral administration of aspirin $(200 \mathrm{mg}$ $\mathrm{kg}^{-1}$, b.w., p.o.) or $\mathrm{NaCl}(9 \%)$. The data are expressed as mean \pm S.E.M. $(n=10), *: p<0.05$ compared to control group and \#: $p<0.05$ compared to colitis group.

\section{Conclusion}

These findings clearly demonstrate that $\mathrm{CDE}$ had potential beneficial effects on aspirin-induced small bowel injury, owing in part to its anti-inflammatory and ROS scavenging activities due to its richness in phenolic compounds especially phenolic acids and flavonoids. 


\section{Ethical consideration}

All procedures on animals in this study were approved with the National Institute of Health recommendations for the use and care of animals.

\section{Conflicts of interest}

The authors declare that they have any competing interests.

\section{Abbreviations}

$\begin{array}{ll}\text { ASPR } & \text { Aspirin } \\ \text { CAT } & \text { Catalase } \\ \text { CDE } & \text { Chamomile decoction extract } \\ \text { GPx } & \text { Glutathione peroxidase } \\ \text { GSH } & \text { Reduced glutathione } \\ \mathrm{H}_{2} \mathrm{O}_{2} & \text { Hydrogen peroxide } \\ \mathrm{MDA} & \text { Malondialdehyde } \\ \text { ROS } & \text { Reactive oxygen species } \\ \text {-SH } & \text { Sulfhydryl groups } \\ \text { SOD } & \text { Superoxide dismutase }\end{array}$

\section{Acknowledgements}

Financial support of the Tunisian Ministry of Higher Education and Scientific Research is gratefully acknowledged. Financial disclosures: none declared.

\section{References}

1 T. D. Warner and J. A. Mitchell, Proc. Natl. Acad. Sci. U. S. A., 2002, 99, 13371-13373.

2 P. Rao and E. E. Knaus, J. Pharm. Pharm. Sci., 2008, 11, 81110.

3 J. R. Vane and R. M. Botting, Thromb. Res., 2003, 110, 255258.

4 L. Yu, Z. Wa, Y. Tao, X. Zhong-Sheng, L. Jie-Yao, H. Ouyang, S. Y. Ti-Dong, Hong-Sheng and C. Qi-Kui, PLoS One, 2015, 10, e0132031.

5 H. Sebai, M. A. Jabri, A. Souli, K. Hosni, S. Selmi, H. Tounsi, O. Tebourbi, S. Boubaker, J. El-Benna and S. Sakly, RSC Adv., 2014, 4, 49831-49841.

6 G. Thiefin, Gastroenterol. Clin. Biol., 2003, 27, 498-510.

7 A. Lewén, P. Matz and P. H. Chan, J. Neurotrauma, 2000, 17, 871-890.

8 D. F. Stowe and A. K. S. Camara, Antioxid. Redox Signaling, 2009, 11, 1373-1414.

9 M. Rigoulet, E. D. Yoboue and A. Devin, Antioxid. Redox Signaling, 2011, 14, 459-468.

10 M. A. Jabri, N. Aissani, H. Tounsi, M. Sakly, L. Marzouki and H. Sebai, Pathophysiology, 2017, 24, 1-8.

11 M. A. Jabri, M. Sakly, L. Marzouki and H. Sebai, Biomed. Pharmacother., 2017, 87, 153-159.

12 D. L. McKay and J. B. Blumberg, Phytother. Res., 2006, 20, 519-530.
13 J. K. Srivastava, E. Shankar and S. Gupta, Mol. Med. Rep., 2010, 3, 895-901.

14 H. Sebai, M. A. Jabri, A. Souli, K. Rtibi, S. Selmi, O. Tebourbi, J. El-Benna and M. Sakly, J. Ethnopharmacol., 2014, 152, 327332.

15 National Research Council, Guide for the Care and the Use of Laboratory Animals, National Institute of Health, Bethesda, 1985, vol. 20, p. 85.

16 Y. Lai, W. Zhong, T. Yu, Z. S. Xia, J. Y. Li, H. Ouyang, T. D. Shan, H. S. Yang and Q. K. Chen, PLoS One, 2015, 10, e0132031.

17 H. H. Draper and M. Hadley, Methods Enzymol., 1990, 186, 421-431.

18 J. Sedlak and R. H. Lindsay, Anal. Biochem., 1968, 25, 192205.

19 G. L. Ellman, Arch. Biochem. Biophys., 1959, 82, 70-77.

20 H. P. Misra and I. Fridovich, J. Biol. Chem., 1972, 247, 31703175.

21 H. Aebi, Methods Enzymol., 1984, 105, 121-126.

22 L. Flohé and W. A. Günzler, Methods Enzymol., 1984, 105, 114-121.

23 E. F. Hartree, Anal. Biochem., 1972, 48, 422-427.

24 B. Dingeon, J. P. Ferry and A. Roullet, Ann. Biol. Clin., 1975, 33, 3-13.

25 M. Payá, B. Halliwell and J. R. Hoult, Biochem. Pharmacol., 1992, 44, 205-214.

26 S. L. Marklund and G. Marklund, Eur. J. Biochem., 1974, 47, 469-474.

27 E. Lien, S. Ren, H. Bui and R. Wang, Free Radical Biol. Med., 1999, 26, 285-294.

28 C. Rice-Evans, N. Miller and G. Paganga, Trends Plant Sci., 1997, 2, 152-159.

29 K. Norren and P. A. Van Leeuwen, Am. J. Clin. Nutr., 2001, 74, 418-425.

30 S. Caltagirone, C. Rossi, A. Poggi, F. O. Ranelletti, P. G. Natali, M. Brunetti, F. B. Aiello and M. Piantelli, Int. J. Cancer, 2000, 87, 595-600.

31 R. J. Gryglewski, R. Korbut, J. Robak and J. Swies, Biochem. Pharmacol., 1987, 36, 317-322.

32 E. A. Bae, M. J. Han, M. Lee and D. H. Kim, Biol. Pharm. Bull., 2000, 23, 1122-1124.

33 L. M. Lichtenberger, T. Phan and S. Okabe, J. Physiol. Pharmacol., 2011, 62, 491-496.

34 S. Tugendreich, C. I. Pearson, J. K. Sagartz and K. Kolaja, Toxicol. Pathol., 2006, 34, 168-179.

35 C. J. McCarthy, L. J. Crofford, J. Greenson and J. M. Scheiman, Am. J. Gastroenterol., 1999, 94, 1218-1223.

36 H. Endo, E. Sakai, T. Kato, S. Umezawa, T. Higurashi, H. Ohkubo and A. Nakajima, J. Gastroenterol., 2015, 50, 378-386.

37 T. Kitahora and P. Guth, Gastroenterology, 1987, 93, 810-817.

38 T. J. Gana, R. Huhlewych and J. Koo, Am. J. Physiol., 1987, 205, 399-405.

39 Y. Hong, P. Xing-chang, W. Shao-kang, Y. Li-gang and S. Guiju, J. Integr. Agric., 2014, 13, 2019-2027.

40 P. Nair, S. S. Kanwar and S. N. Sanyal, Nutr. Hosp., 2006, 21, 638-649. 
41 M. A. Jabri, K. Rtibi, H. Tounsi, K. Hosni, A. Souli, J. ElBenna, L. Marzouki, M. Sakly and H. Sebai, RSC Adv., 2015, 5, 64865-64877.

42 M. A. Jabri, S. Hajaji, L. Marzouki, J. El-Benna, M. Sakly and H. Sebai, RSC Adv., 2016, 6, 16645-16655.

43 M. B. Grisham, Lancet, 1994, 344, 859-861.

44 D. Jourd'heuil, Z. Morise, E. M. Conner and M. B. Grisham, J. Clin. Gastroenterol., 1997, 25, 61-72.

45 T. P. J. Mulder, H. W. Versparget, A. R. Janssens, P. A. F. De Bruin, A. S. Pena and C. B. H. W. Lamers, Gut, 1991, 32, 1146-1156.

46 B. Sido, V. Hack, A. Hochlehnert, H. Lipps, C. Herfarth and W. Droge, Gut, 1998, 42, 485-492.

47 J. M. Reimund, Nutr. Clin. Metab., 2002, 16, 275-284.

48 D. Bonnefont-Rousselot, Biochimie, 2004, 86, 903-911.

49 H. Esterbauer, J. Gebicki, H. Puhl and G. Jurgens, Free Radical Biol. Med., 1992, 13, 341-390.
50 M. Hurtado-Nedeleca, P. M. C. Dang, R. C. Monteiroa, J. ElBenna and M. A. Gougerot-Pocidaloa, French. Med. Mag., 2014, 462, 25-38.

51 E. Cadenas and K. J. Davies, Free Radical Biol. Med., 2000, 29, 222-230.

52 J. Nève, Nutr. Clin. Metab., 2002, 16, 292-300.

53 M. A. Jabri, S. Maman, K. Rtibi, L. Marzouki, J. El-Benna, M. Sakly and H. Sebai, Lipids Health Dis., 2016, 15, 1-10.

54 J. L. Cracowski, B. Bonaz, G. Bessard, J. Bessard, C. Anglade and J. Fournet, Am. J. Gastroenterol., 2002, 97, 99-103.

55 I. Javadi and S. Emami, Med. Arh., 2015, 69, 229-231.

56 D. A. Kogiannou, N. Kalogeropoulos, P. Kefalas, M. G. Polissiou and A. C. Kaliora, Food Chem. Toxicol., 2013, 61, 152-159.

57 C. C. Chen, B. L. Wei, S. H. Loke and W. F. Chiou, Am. J. Chin. Med., 2007, 18, 89-100.

58 J. Legault, T. Perron, V. Mshvildadze, K. Girard-Lalancette, S. Perron, C. Laprise, P. Sirois and A. Pichette, J. Med. Food, 2011, 14, 1127-1134. 